\title{
HIV infection: just an infectious disease?
}

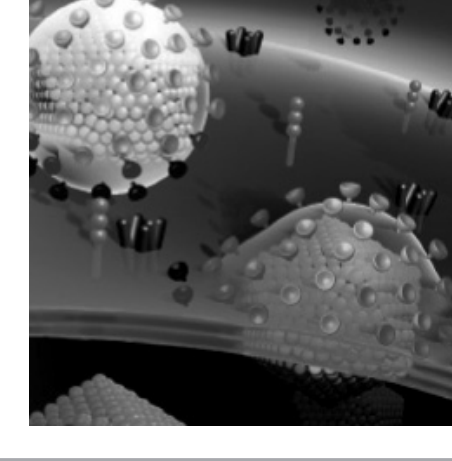

\section{5th International AIDS Society Conference, Cape Town, South Africa, 19-22 July 2009}

In 2007, 2.5 million people have been newly infected with HIV and 2.I million people died from AIDS, worldwide. HAART has turned AIDS into a manageable disease. However, numerous questions remain unanswered, such as the when to initiate HAART and what are the most effective doses of antiretroviral drugs. HIV reservoirs and how they could be attacked by therapeutic strategies is another issue. The 5th International AIDS Society (IAS) Conference in Cape Town, South Africa, focused on these subjects as well as on the hotly discussed funding budget. As has been indicated in the Sydney Declaration 2 years ago, 10\% of the funding budget must be spent on clearly defined fields of HIV research. The following article presents highlights of the IAS Conference 2009.

Since 2007, 2.5 million people have been newly infected with HIV and 2.1 million people died from AIDS, worldwide [101]. One goal of the Sydney Declaration, issued during the 4th International AIDS Society (IAS) Conference in 2007, was that HIV programs should spend up to $10 \%$ of the funding budget on research in order to answer the following questions:

" What are the reasons for the high early mortality rate in patients on HAART?

- Are lower doses of antiretroviral drugs equally effective and if yes, is it possible to treat more people by sparing drugs?

- Should HAART be started early in order to prevent TB in HIV-1-infected persons?

The 5th IAS Conference, which took place in Cape Town, South Africa, focused in part on answering these aforementioned questions by presenting data on:

- Immunological mechanisms in HIV-1 infection

- Vaccine development

- Management strategies with respect to treatment

- Policies in the field of HIV-1 infection and AIDS

It is well documented that early HIV-1 infection is characterized by the death of both infected and uninfected $\mathrm{CD}^{+}$cells, often resulting in severe $\mathrm{CD}^{+}{ }^{+}$cell depletion in the GI tract. HIV-1 infection in humans rapidly induces polyclonal activation and terminal differentiation of B cells in both the blood and in gut-associated lymphoid tissue, along with the loss and damage of germinal centers [1]. Consequently, there is a decline in HIV-1induced antibody responses and a delay in plasma antibody responses to HIV-1 [1]. In context with HIV-1 replication, natural killer (NK) cells depend on the killer immunoglobulin-like receptor/HLA subtype of the cell to work [2]. Therefore, prerequisites of an effective AIDS vaccine are an induction of significant levels of broadly neutralizing antibodies before HIV-1 transmission and priming for rapid innate responses of anti-HIV-1 factors, for example, of NK cells [1]. Having been awarded the Nobel Prize in Medicine in October 2008, Francoise Barre-Sinoussi was recently asked why the development of an AIDS vaccine is so difficult. Her explanation implied the variability of the virus and the storage of HIV-1 in reservoirs such as lymph nodes of the intestinal region. In addition, HIV-1 infection does not share many features that are traditionally used in designing a vaccine, thus making the development of an AIDS vaccine challenging [3].

Which cells are acting as reservoirs? The central memory $\mathrm{CD}^{+}{ }^{+}$cells and the transitional memory $\mathrm{CD}^{+}$cells have been identified as reservoirs for HIV-1 [4]. In patients demonstrating immune reconstitution upon HAART, HIV-1 persists primarily in central memory $\mathrm{CD}^{+}$cells but in aviremic persons with low $\mathrm{CD}^{+}{ }^{+}$cell counts proviral DNA was preferentially detected in transitional memory $\mathrm{CD}^{+}$ cells [4]. Therefore, not only is the virus a target for antiretroviral compounds, but proliferating memory $\mathrm{T}$ cells and the NK cells might also be targets.
Christine Armbruster 2nd Medical Department/Otto Wagner Spital Vienna, Mantlergasse 23/2/12, A-II30 Vienna, Austria Tel.: +43676 626 4084; Fax: +43 19|1 2901; christine.armbruster@gmx.at 
In the light of effective antiretroviral therapy (ART) one question remains: why are HIV-1 infected persons dying in the era of HAART? One explanantion is the delayed recognition of HIV-1 infection and the late initiation of ART. Data from the Swiss HIV Cohort Study, including 1915 patients having been diagnosed to be HIV-infected between 1998 and 2007 (group A) and 1730 treatment-naive patients characterized by 200 or more $\mathrm{CD} 4^{+}$cells $/ \mathrm{mm}^{3}$ (group B,) demonstrated that the median $\mathrm{CD}^{+}{ }^{+}$cell count at combination ART (cART) initiation was low (207 and $253 \mathrm{CD}^{+}$cells $/ \mathrm{mm}^{3}$ in group A and $\mathrm{B}$, respectively) due to late presentation of the patients [5]. The Data Collection on Adverse Events of Anti-HIV Drugs (D:A:D) study, for which 23,437 patients have been recruited, demonstrated a clear relationship between the severity of immune suppression and death from both AIDS-defining and non-AIDS-defining malignancies [6]. At the IAS Conference, this year a session was entitled 'Delay in starting treatment is common in ART programs'. Ingrid Bassett presented alarming data from a prospective study undertaken in Durban, South Africa. A total of 3401 patients were screened, $82 \%$ were tested, of whom $52 \%$ tested positive for HIV. Only 154 HIV-1-infected patients with less than $200 \mathrm{CD}^{+}$cells $/ \mathrm{mm}^{3}$ started treatment within 11 months and $21 \%$ of the patients died before initiation of therapy. These results are in line with an epidemiological trial performed 15 years ago (1994-1998) in Austria, which demonstrates a delay in seeking care of 1665.5 days after having been tested positive for HIV-1 [7]. Very recently this subject has been re-evaluated, showing that HIV-1-infected patients are still admitted to the hospital with a median delay of 7 months [Armbruster C, Katzian C, Unpublished Data].

The first task of the President's Emergency Plan for AIDS Relief (PEPFAR), inherited by the Obama administration, is to diagnose HIV infection early in order to be able to initiate prevention and treatment strategies $[8]$. We are far more successful in providing cART to women than to men, based on behavioral differences between sexes and on antenatal care services that represent an important entry point to HIV/AIDS testing and treatment. Only $6 \%$ of African male patients report homosexual behavior [9]. Cultural, political and religious hostility towards men who have sex with men are the main barriers to the implementation of HIV programs for this group of patients.
Although ART shortly after exposure to HIV-1 has been proven to be effective, this strategy is not standard of care in persons with risky behavior.

Two prevention strategies are currently being discussed: male circumcision and the human papillomavirus (HPV) vaccination. In contrast to two trials demonstrating that male circumcision represents an effective strategy, recent results of an observational study showed that male circumcision failed in reducing HIV-1 transmission [10-12].

Human papillomavirus infection as a predisposing factor for anal cancer is another concern and HPV vaccination might prevent cancer development. However, study results presented at the IAS Conference 2009 were discouraging. Following vaccination, only $34,6.4$ and $3.2 \%$ of the men developed antibodies to HPV-16, HPV-18 and to both HPV subtypes, respectively.

The second task of PEPFAR was also a subject at the IAS Conference 2009. Antony Fauci presented recent data demonstrating that ART above the threshold of $350 \mathrm{CD}^{+}$cells $/ \mathrm{mm}^{3}$ led to less illness due to AIDS-associated complications, longer survival, more complete immune reconstitution and lower long-term costs. $\mathrm{He}$ concluded: "Everything points to earlier HIV therapy". Looking back more than 15 years, David Cooper and his group undertook a placebo-controlled study evaluating the efficacy of zidovudine in HIV-1-infected patients with more than $400 \mathrm{CD}^{+}$lymphocytes. Asymptomatic HIV-1-infected patients benefitted from early treatment [13]. In November 2008 guidelines were adapted according to the new developments in the field of early cART [102]. The Strategic Timing of AntiRetroviral Therapy (START) trial is currently recruiting HIV-1infected patients to evaluate early cART, at a $\mathrm{CD}^{+}{ }^{+}$cell count of more than 500 cells $/ \mathrm{mm}^{3}$, with respect to mortality and illness. Jose Gatell warned at the IAS Conference 2009 that "we cannot wait until completion of the START study to make decisions."

Strategies making the third task of PEPFAR to sustain people on lifelong treatment realistic included, for example, the simplification of ART. Three examples are noteworthy:

- Boosted darunavir monotherapy works well

- Once-daily lopinavir/ritonavir is as safe and equally effective as twice-daily dosing

- The integrase inhibitor GSK-572 looks good as a once-daily regimen without ritonavir boosting 
However, despite these developments, money remains the crucial factor. At the opening session of the conference, scientists and activists commented on the financial crisis that the G8 leaders are still required to meet their commitments to finance universal access to treatment and prevention despite the economic crisis. However, alternative solutions are still urgently required. HIV care at home is one example of a cost-effective approach. HIV care at home has been proved to be not only cost-effective, but also feasible and safe, as has been published several years ago [14]. A homecare and nurse-initiated ART project has been performed in Uganda recently. Similar $\mathrm{CD}_{4}{ }^{+}$cell count recovery and equal levels of adherence could be demonstrated in both, the home-based HIV care and in the healthcare facility group.

Funding by various organizations and by the pharmaceutical industry represents the basis for HIV care in developing countries. A concerted action is urgently required to spend the funding budget on clearly defined fields of HIV research. One step toward this goal is to focus up to $10 \%$ of the budget to evaluate:

- The reasons for the high mortality rate in patients on HAART

- The effectiveness of lower doses of antiretroviral drugs

- The best timing for HAART to be started

Financial \& competing interests disclosure

The author has no relevant affiliations or financial involvement with any organization or entity with a financial interest in or financial conflict with the subject matter or materials discussed in the manuscript. This includes employment, consultancies, honoraria, stock ownership or options, expert testimony, grants or patents received or pending, or royalties.

No writing assistance was utilized in the production of this manuscript.

\section{Bibliography}

1 Levesque MC, Moody MA, Hwang KK et al.: Polyclonal B cell differentiation and loss of gastrointestinal tract germinal centers in the earliest stages of HIV-1 infection. PLoS Med. 6(7), e1000107 (2009).

2 Alter G, Martin MP, Teigen N et al.: Differential natural killer cell-mediated inhibition of HIV-1 replication based on distinct KIR/HLA subtypes. J. Exp. Med. 204(12), 3027-3036 (2007).

3 Armbruster C: HIV-1 infection: recent developments in treatment and current management strategies. Anti-Infect. Agents Med. Chem. 7(3), 201-214 (2008).

4 Chomont N, El-Far M, Ancuta P et al.: HIV reservoir size and persistence are driven by T cell survival and homeostatic proliferation. Nat. Med. 15(8), 893-900 (2009).

5 Wolbers M, Bucher HC, Furrer $\mathrm{H}$ et al.: Delayed diagnosis of HIV infection and late initiation of antiretroviral therapy in the Swiss HIV Cohort Study. HIV Med. 9(6), 397-405 (2008).

6 Monforte A, Abrams D, Pradier C et al.: HIV-induced immunodeficiency and mortality from AIDS-defining and non-AIDS-defining malignancies. AIDS 22(16), 2143-2153 (2008).
7 Armbruster C, Kriwanek S, Vorbach H: Gender-specific differences in the natural history, clinical features, and socioeconomic status of HIV-infected patients: experience of a treatment centre in Vienna. Wien. Klin. Wochenschr. 112(17), 754-760 (2000).

8 Navario P: PEPFAR's biggest success is also its largest liability. Lancet 374(9685), 184-185 (2009).

9 Smith AD, Tapsoba P, Peshu N, Sanders EJ, Jaffe HW: Men who have sex with men and HIV/AIDS in subSaharan Africa. Lancet 374(9687), 416-422 (2009).

10 Bailey RC, Moses S, Parker CB et al.: Male circumcision for HIV prevention in young men in Kisumu, Kenya: a randomised controlled trial. Lancet 369(9562), 643-656 (2007).

11 Gray RH, Kigozi G, Serwadda D et al.: Male circumcision for HIV prevention in men in Rakai, Uganda: a randomised trial. Lancet 369(9562), 657-666 (2007).

12 Wawer MJ, Makumbi F, Kigozi G et al.: Circumcision in HIV-infected men and its effect on HIV transmission to female partners in Rakai, Uganda: a randomised controlled trial. Lancet 374(9685), 229-237 (2009).
13 Cooper DA, Gatell JM, Kroon S et al.: Zidovudine in persons with asymptomatic $\mathrm{HIV}$ infection and $\mathrm{CD} 4^{+}$cell counts greater than 400 per cubic millimeter. The European-Australian Collaborative Group. N. Engl. J. Med. 329(5), 297-303 (1993).

14 Armbruster C, Vetter N: Heimbetreuung von AIDS-Patienten aus medizinischer und pflegerischer Sicht - ein Wiener Projekt. Acta Med. Austriaca 21(1), 14-16 (1994).

\section{- Websites}

101 UNAIDS/WHO. AIDS Epidemic Update. Geneva, Switzerland: UNAIDS/WHO, 2007. http://data.unaids.org/pub/ EpiReport/2007/03-Introduction-2007_ EpiUpdate_eng.pdf (Accessed 8 August 2009)

102 AIDSinfo. Guidelines for the use of antiretroviral agents in HIV-1 infected adults and adolescents, www.aidsinfo.nih.gov/ guidelines/default.aspx? MenuItem=guidelines (Accessed 16 August 2009) 